\title{
Raymond Trousson, Rousseau 1800-1912
}

\section{Catriona Seth}

\section{(2) OpenEdition}

\section{Journals}

\section{Édition électronique}

URL : http://journals.openedition.org/studifrancesi/3770

DOI : 10.4000/studifrancesi.3770

ISSN : 2427-5856

\section{Éditeur}

Rosenberg \& Sellier

\section{Édition imprimée}

Date de publication : 1 décembre 2012

Pagination : 582

ISSN : 0039-2944

\section{Référence électronique}

Catriona Seth, «Raymond Trousson, Rousseau 1800-1912 », Studi Francesi [En ligne], 168 (LVI | III) |

2012, mis en ligne le 30 novembre 2015, consulté le 07 mars 2021. URL : http://

journals.openedition.org/studifrancesi/3770; DOI : https://doi.org/10.4000/studifrancesi.3770

\section{Ce document a été généré automatiquement le 7 mars 2021.}

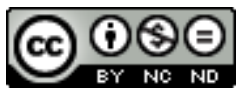

Studi Francesi è distribuita con Licenza Creative Commons Attribuzione - Non commerciale - Non opere derivate 4.0 Internazionale. 


\title{
Raymond Trousson, Rousseau 1800-1912
}

\author{
Catriona Seth
}

\section{RÉFÉRENCE}

RAYMOND TROUSSON, Rousseau 1800-1912, Paris, P. U. de Paris-Sorbonne, «Mémoire de la critique», 2012, pp. 718.

1 Si Jean-Jacques Rousseau fait partie du petit groupe d'individus qui a eu la curieuse expérience d'apprendre qu'on l'avait supposé mort - un article du «Courrier d'Avignon" avait cru bon, en 1776, de donner foi à cette rumeur, propagée à la suite de l'accident de Ménilmontant - alors que l'écrivain avait encore deux ans à vivre, il est resté, après sa "panthéonisation» en 1794, une figure vivante des débats politiques et esthétiques. Dans la série «Mémoire de la critique», dont chacun connaît l'intérêt, Raymond Trousson, grand spécialiste de Jean-Jacques, et l'un des maîtres d'œuvre, avec Frédéric S. Eigeldinger, d'une édition du tricentenaire lancée chez Champion, nous offre un passionnant Rousseau 1800-1912. Les grands noms voisinent, dans ce fort volume, avec des auteurs oubliés, les billets d'humeur avec les textes censés présenter un point de vue canonique sur l'auteur du Contrat social. Si l'on retrouve avec plaisir Germaine de Staël, auteur dès 1788 de Lettres sur le caractère et sur les écrits de JeanJacques Rousseau, mais qui ouvre ici l'anthologie critique grâce à un passage de De la littérature (1800) ou encore un Alexandre Dumas inattendu avec un extrait de Louis XVI et la Révolution (1850), on y relève également la critique d'un Lamennais face au "péché d'indifférence» de Jean-Jacques ou encore les textes de chansonniers comme Béranger et Chaponnière dont le Gavroche des Misérables reprend le refrain: "C'est la faute à Voltaire [...] / C'est la faute à Rousseau». Chacun fera ici des découvertes. La sélection d'extraits est précédée d'une savante préface qui dessine le devenir d'un Rousseau porté aux nues par les révolutionnaires, puis voué aux gémonies par une réaction conservatrice qui dénonce aussi bien le penseur politique que l'autobiographe, «historien complaisant de ses propres infamies», comme l'écrit l'abbé Proyart en 1800. 
Nombreux sont les fils de Jean-Jacques, à l'instar de Chateaubriand ou de Bonaparte, à tourner casaque et à critiquer celui dont les œuvres ont nourri leur jeunesse. Si l'Empire ou la Restauration sont des périodes peu fastes pour le souvenir de Rousseau, la Révolution de 1848 tend à réhabiliter chez certains la postérité du Genevois. On ne saurait assez conseiller, à toute personne intéressée par la réception de Rousseau, la lecture de cet ouvrage, dont plus de deux cents des quelque sept cents pages portent sur la période antérieure à 1850 . 